\title{
A note on the effect of breed on the feeding behaviour of pigs and variation in feed intake, feed conversion ratio and feeding behaviour between pigs of the same breed
}

E. Magowan, M.E.E. McCann

Agri-Food and Biosciences Institute, Hillsborough, United Kingdom

Email: elizabeth.magowan@afbini.gov.uk

Introduction In scientific studies the effect of breed on feed intake is often determined on groups of pigs (e.g. McCann et al. 2008). However, there is a lack of information regarding the feed intake or feeding behaviour of individual pigs in group housing and from different breeds. The objective of this study was to investigate the variation in feed intake and feeding behaviour of group housed pigs representing three commercially available breeds.

Materials and methods Twelve LR x LW F1 dams were inseminated with mixed semen from either the PIC 337, PIC 327 or Tempo breed. Piglets were weaned (28 days of age) and penned together in groups of 20, respective of breed. At 10 weeks of age, 72 pigs (12 boars and 12 gilts from each breed) were selected according to weight and placed in groups of 8 (which were balanced for breed and weight) in the finishing accommodation. Pigs were offered feed from ACEMO 54 electronic feeders from 10 weeks of age. At 12 weeks of age the average weight of PIC 327, PIC 337 and Tempo pigs was $38.9,38.8$ and $38.0 \mathrm{~kg}$ respectively. Feed intake, time of feed and duration of feeding was recorded on an ongoing basis between 12 weeks of age and at finish (152 days of age). Pigs were weighed again at finish. The effect of breed and gender on average daily feed intake (ADFI), feed conversion ratio (FCR) and feeding behaviour (intake/visit/24h, total visits/24h, average time spent/visit and total time spent feeding/24hr) was tested using analysis of variance (Genstat version 10 ) with 12 week weight used as a covariate. Feeding behaviour data where pigs were found to eat less than $30 \mathrm{~g}$ but were in the feeder for 30 minutes or more were excluded. The standard deviation (SD) and coefficient of variation (CV) for ADFI, FCR and feeding behaviour data were also calculated for the 24 pigs representing each breed.

Results Breed had no significant effect on the ADFI, FCR or the total time spent feeding/24hr (Table 1). However, Tempo pigs had fewer visits to the feeder/24hr but each visit was longer and they ate more feed within that visit compared with pigs from the PIC 327 or PIC 337 breeds (Table 1). The CV of ADFI was higher in the group of Tempo pigs compared with that of the PIC 327 and PIC 337 pigs (Table 2). The CV of FCR was lowest in PIC 337 pigs. The CV of feeding behaviour (intake/visit/24h, total number of visits/24h and average time spent/visit) was markedly greater than that of ADFI and FCR. The SD and CV of feeding behaviour also differed across the groups of pigs from the different breeds (Table 2). There were no significant interactions between breed and gender. Furthermore, there was no significant effect of gender on feeding behaviour (intake/visit/24h (average $248 \mathrm{~g}$ ); total visits/24h (average 10.9); average time spent/visit (average 429s) and total time spent feeding/24h (average $61.7 \mathrm{~min}$ )). Gender did not significantly effect the ADFI of pigs but gilts had a significantly $(\mathrm{P}<0.01)$ poorer FCR $(2.31)$ than boars $(2.18)$.

Table 1 The effect of breed on ADFI, FCR and feeding behaviour between 12 weeks of age and finish

\begin{tabular}{llllll}
\hline \hline & PIC 327 & PIC 337 & Tempo & SEM & Sig \\
\hline ADFI (g/day) & 2073 & 2240 & 2139 & 53.7 & NS \\
FCR & 2.23 & 2.20 & 2.31 & 0.041 & NS \\
Intake/visit/24h (g) & $190^{\mathrm{a}}$ & $230^{\mathrm{a}}$ & $320^{\mathrm{b}}$ & 19.9 & $<0.001$ \\
Total visits/24h & $13.8^{\mathrm{b}}$ & $11.8^{\mathrm{b}}$ & $7.3^{\mathrm{a}}$ & 1.11 & $<0.001$ \\
Av Time spent/visit (s) & $307^{\mathrm{a}}$ & $375^{\mathrm{a}}$ & $599^{\mathrm{b}}$ & 40.0 & $<0.001$ \\
Total time spent feeding/24h (minutes) & 59.4 & 60.0 & 65.7 & 2.65 & $\mathrm{NS}$ \\
\hline \hline
\end{tabular}

$\overline{\mathrm{a}, \mathrm{b}, \mathrm{c},}$ numbers with the same superscripts are not significantly different $(\mathrm{P}>0.05)$

Table 2 The SD and CV of ADFI, FCR and feeding behaviour within each group of pigs (24) from the different breeds.

\begin{tabular}{|c|c|c|c|c|c|c|}
\hline & \multicolumn{2}{|c|}{ PIC 327} & \multicolumn{2}{|c|}{ PIC 337} & \multicolumn{2}{|c|}{ Tempo } \\
\hline & SD & $\mathrm{CV}$ & SD & $\mathrm{CV}$ & SD & $\mathrm{CV}$ \\
\hline ADFI (g/day) & 233 & 0.112 & 251 & 0.112 & 335 & 0.157 \\
\hline FCR & 0.229 & 0.102 & 0.131 & 0.059 & 0.237 & 0.103 \\
\hline Intake /visit/24hr (g) & 96.2 & 0.513 & 94.9 & 0.394 & 96.6 & 0.309 \\
\hline Total visits $/ 24 \mathrm{~h}$ & 6.1 & 0.434 & 6.1 & 0.534 & 3.4 & 0.454 \\
\hline Av Time spent/visit (s) & 160 & 0.524 & 163 & 0.430 & 232 & 0.390 \\
\hline Total time spent feeding/24h (minutes) & 9.3 & 0.157 & 13.2 & 0.221 & 14.3 & 0.217 \\
\hline
\end{tabular}

Conclusion This study suggests that although the average daily feed intake and feed conversion ratio of pigs between breeds may not differ significantly, their feeding behaviour can be very different. Furthermore the variation in feeding behaviour across all breeds was greater than the variation in feed intake and feed conversion ratio observed in the same group of pigs. Further studies with increased replication are required to validate these conclusions.

Acknowledgements The co-operation of PCM regards the use of the research facility to conduct this study is appreciated.

Reference

McCann, M.E.E., Beattie, V.E., Watt, D., Moss, B.W. 2008. Irish Journal of Agriculture and Food Research 47, 171-185. 